\title{
Progression of duodenal adenomatosis in familial adenomatous polyposis: due to ageing of subjects and advances in technology
}

\author{
Elisabeth M. H. Mathus-Vliegen - Karam S. Boparai • \\ Evelien Dekker • Nan van Geloven
}

Published online: 18 March 2011

(c) The Author(s) 2011. This article is published with open access at Springerlink.com

\begin{abstract}
Familial adenomatous polyposis patients are at risk of duodenal cancer. Surveillance is indicated and the extent of duodenal polyposis is quantified by the Spigelman staging system. We noticed an impressive increase in high Spigelman stages over the years and therefore decided to investigate whether this increase might be due to the time-lapse since the inception of surveillance or related to improvements in endoscopic imaging and/or changes in dysplasia-reporting. Patients who were investigated by the same endoscopist since 1980 in at least 2 different episodes of technical improvements were eligible. The period 1980-2009 was divided into 4 episodes using the following landmarks: replacement of fibre-endoscopes by video-endoscopes in 1987, change in processors in 1995, change in image resolution in 2000, and change in dysplasia-reporting in 2006. An increase in Spigelman stages from low stages (0-II 100\%) to high stages (III 28.1\%, IV $43.8 \%$ ) was seen (median follow-up: 19.5 years). In patients who progressed, a median of 4 years elapsed before progression by one stage occurred and 7 years to progress by two stages. In a mixed-model analysis, both time-lapse and technical improvements were determinant factors for duodenal disease progression. When both factors were introduced in the model, the time-lapse as well as the change in image resolution and dysplasia-ranking contributed
\end{abstract}

E. M. H. Mathus-Vliegen ( $₫)$ · K. S. Boparai · E. Dekker Department of Gastroenterology and Hepatology, Academic Medical Centre, University of Amsterdam, Meibergdreef 9, 1105 AZ Amsterdam, The Netherlands e-mail: e.mathus-vliegen@amc.uva.nl

N. van Geloven

Department of Clinical Epidemiology and Biostatistics, Academic Medical Centre, University of Amsterdam, Meibergdreef 9, 1105 AZ Amsterdam, The Netherlands consistently in increasing Spigelman scores and stages. The impressive increase in severity of duodenal polyposis is determined by time-lapse, technological advances and change in dysplasia-reporting. These results might call for a revised Spigelman classification.

Keywords Familial adenomatous polyposis - FAP . Duodenal adenomatosis - Spigelman staging system . Endoscopy

\section{Introduction}

Familial adenomatous polyposis (FAP) is an inherited autosomal dominant condition caused by a mutation of the adenomatous polyposis coli (APC) gene on the long arm of chromosome $5[1,2]$. The most conspicuous feature of the disease is the early development of thousands of adenomas in the colon. Colorectal cancer develops in virtually all affected members by the 5th decade of life unless prophylactic colectomy is performed. Extra-colonic intestinal manifestations include fundic gland polyposis and antrum adenomas in the stomach and duodenal and small intestinal adenomas. After prophylactic subtotal colectomy, the risk of subsequent upper gastrointestinal cancer or desmoid disease is greater than the risk of cancer in the retained rectal segment after ileorectal anastomosis [3-6]. The absolute risk of duodenal cancer over lifetime is estimated to be 3-5\% [7-10].

This has resulted in a discussion about the relevance of surveillance of the duodenum and its benefits in terms of survival [10-17]. In an attempt to quantify the extent of duodenal polyposis, a staging system has been developed by Spigelman et al. [18]. This classification includes endoscopic features (number and size of adenomas) and histopathological characteristics (type of adenoma and 
degree of dysplasia). Although the Spigelman staging has never been validated, it has facilitated a better understanding of the natural history of duodenal polyposis and has attempted to link the stage of duodenal polyposis to the severity of the disease. It has been accepted as the gold standard for risk-stratification of duodenal cancer. The different stages are used to determine the interval of surveillance and the need for intervention.

In the last 2 decades, an impressive technical development in the endoscopic equipment has resulted in improved endoscopic imaging quality. Furthermore, the Vienna classification has changed the nomenclature of dysplasia into negative for dysplasia, low grade dysplasia (LGD) and high grade dysplasia (HGD) [19]. Only Saurin et al. [9] have indicated how they changed their Spigelman scoring according to the new Vienna classification, scoring 1 point for LGD and 3 points for HGD.

Over the years, we have the impression that the number of high Spigelman stages is increasing. We postulated several possible reasons for this increase such as the increased age and prolonged survival of FAP patients, the differences in ratings between consecutive endoscopists, the technical improvement in endoscopic imaging and the recent changes in the dysplasia classification for pathologists. A last possible explanation might be the difference in type of the endoscopes used for the assessment. The Spigelman classification was originally developed for only that part of the duodenum that is visible by a sideward-viewing endoscope, i.e. the first and second part of the duodenum [18], whereas a larger area up to the duodenojejunal ligament can be visualized with a regular forward-viewing endoscope.

The aim of this study was to examine whether the increase in Spigelman stages was due to

1. the time lapse since the start of upper digestive tract surveillance;

2. the improved endoscopic image quality
a. between fibre-endoscopes and video-endoscopes
b. due to changes in processors
c. between low and high resolution systems;

3. the change in the classification of dysplasia.

\section{Materials and methods}

\section{Patients}

At our institute, a tertiary referral academic centre, surveillance of FAP patients started in 1975. To exclude a possible influence of different endoscopic assessments and ratings by consecutive endoscopists, we included only patients who were investigated by one endoscopist (E.M-V) since 1980 over time and who were examined in at least 2 different episodes (see below). In the period 1992-2000, patients participated in the DAF trial (duodenal adenomatosis in FAP patients), which required a 2-yearly upper endoscopic surveillance with a forward-viewing endoscope with multiple biopsies taken from the polyps if present and with multiple random biopsies in the absence of polyps [7, 20]. Since 1997, the Spigelman stage was assessed using both a forward-viewing and a sideward-viewing endoscope, enabling staging both with and without the papillary region.

Patients remained in the study till the censory date of January 1, 2009 or the date of decease. Patients who underwent surgery, polypectomy or endoscopic mucosal resection of duodenal polyps or the papilla, which might have resulted in down-staging [21], were included until the date of the intervention.

\section{Methods}

The period between 1980 and 2009 was divided into 4 episodes using the following landmarks: the replacement of fibre-endoscopes by video-endoscopes in 1987, the change from EVIS-100 to EVIS-130/140 (End Video Inform System, Olympus, Tokyo, Japan) processors in 1995, the change from Low Resolution to High Resolution (EVIS-EXERA160; End Video Inform System-EXelentERA, Olympus, Tokyo, Japan) endoscopes in 2000 and the Vienna classification of dysplasia introduced in 2006 (Fig. 1). The Spigelman score and stage were calculated without inclusion of the papilla. Since 1997, a separate Spigelman score and stage was calculated which included the papilla, which in case of a papillary adenoma and in case of a higher grade of dysplasia in biopsies of the papilla contributed to a higher Spigelman score and stage. For this separate analysis, only patients with an endoscopy before and after 1997 were included. After the introduction of the Vienna classification [19], dysplasia scores according to Saurin et al. [9] were used: scoring 1 point for LGD and 3 points for HGD.

\section{Statistics}

Patient characteristics are described as median and ranges. Patients entered and left the study at different times, the latter in case of death or endoscopic or surgical interventions. Some patients had a consistent 2-yearly follow-up, dictated by the DAF study, whereas others had their follow-up as indicated by the Spigelman stage (Table 1). Therefore, a linear mixed model analysis with fixed and random effects was used. For each comparison models with different correlation structures were built and the best fitting model with the lowest 2-restricted Log Likelihood was taken. Covariance types used in the model building were variance components and autoregressive covariance 
Fig. 1 Mean Spigelman score over time and the influences of changes in equipment and pathology

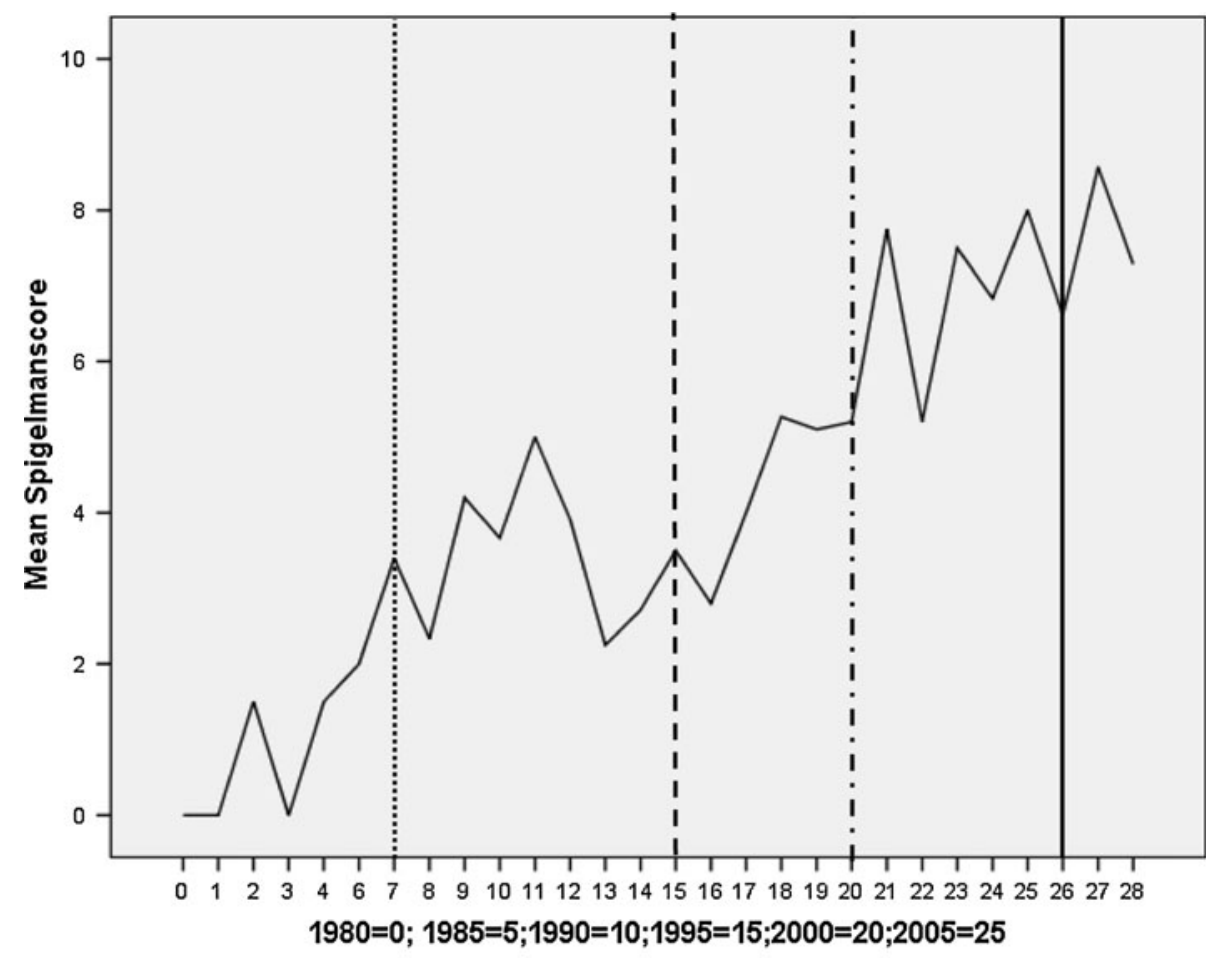

... depicts the change from fibre-endoscopes to videoendoscopes

- - - depicts the change from EVIS 100 to EVIS 130-140 processors

- . - . - depicts the change from Low Resolution to High

Resolution endoscopes

- depicts the change from a 4-score PA dysplasia

ranking into a 3-stage Vienna dysplasia ranking structures. The dependent variables included the Spigelman score (0-12 points) and in a secondary analysis the Spigelman score with inclusion of the papilla. Fixed factors were the time lapse since the start of screening and the 4 period indicators. A random intercept and a random slope per patient were included to account for the correlations between measurements belonging to the same patient. First, each of the fixed factors was introduced into a single model followed by a model that included the fixed factor time lapse and one of the 4 period indicators. To avoid intercorrelation of the period indicators with the time variable, the 4 period indicators were not simultaneously offered to the model. Despite its low number of categories (0-IV stages) a similar confirmatory linear mixed model analysis was performed on the Spigelman stages. A $P$ value of $<0.05$ was considered significant.

\section{Results}

In our centre, 160 patients with FAP are under surveillance. Of this cohort, 32 patients were eligible as they underwent an endoscopy in at least 2 separate periods and were all investigated by the same endoscopist (E.M-V). In this group of 32 patients, colectomy was performed at a median age of 28 years and screening of the upper digestive tract started a median of 10 years later (Table 2). The median follow-up was 19.5 years (range, 8-28 years); patients received a median of $6.5(2-17)$ endoscopies for surveillance of the duodenum resulting in a total of 210 endoscopies for analysis.

Fifteen patients did not complete the follow-up period till the censory date of January 1, 2009. Five patients (4 males) died, one at 40 years because of cancer at the ileoanal anastomosis, one patient died from a jejunal cancer at the age of 57 years and one from a peripapillary cancer at the age of 59 years. A female patient died at the age of 55 years from lung cancer, a male of 81 years died from lung emphysema. Ten patients ( 5 males, 5 females) had surgery or endoscopic intervention for duodenal adenomatosis. Two patients underwent a Whipple procedure and two a pancreas-preserving duodenectomy. One patient underwent a polypectomy of a duodenal polyp, two patients a papillectomy because of a growing papillary 
Table 1 Scoring system related to the Spigelman classification to estimate the severity of duodenal adenomatous polyposis and the risk of duodenal cancer development. The number and size of the polyps, the histological characteristics and the degree of dysplasia are given a score between 0 and 3 . The 4 scores are summed up and the overall score determines the Spigelman stage and the suggested follow-up

\begin{tabular}{|c|c|c|c|c|}
\hline Score & Number of polyps & Size of polyps & Histological characteristics & Degree of dysplasia \\
\hline 0 & 0 & No polyps & No adenomas & No dysplasia \\
\hline 1 & $1-4$ & $1-4 \mathrm{~mm}$ & Tubular adenoma & Mild dysplasia \\
\hline 2 & $5-20$ & $5-10 \mathrm{~mm}$ & Tubulovillous adenoma & Moderate dysplasia \\
\hline 3 & $>20$ & $>10 \mathrm{~mm}$ & Villous adenoma & Severe dysplasia \\
\hline Spigeln & \multicolumn{3}{|c|}{ Spigelman stage } & Suggested follow-up \\
\hline 0 & \multicolumn{3}{|c|}{0} & Every 5 year \\
\hline $1-4$ & \multicolumn{3}{|c|}{ I } & Every 5 year \\
\hline $5+6$ & \multicolumn{3}{|c|}{ II } & Every 2 years \\
\hline $7+8$ & \multicolumn{3}{|c|}{ III } & Every year \\
\hline $9-12$ & \multicolumn{3}{|c|}{ IV } & Every 6 months \\
\hline
\end{tabular}

Table 2 Characteristics of patients entering the study on duodenal adenomatous polyposis

\begin{tabular}{lc}
\hline$N$ (male/female) & $32(16 / 16)$ \\
Age at colectomy-years (median and range) & $28(9-52)$ \\
Age when starting upper digestive tract screening-years median and range) & $38(13-65)$ \\
Age at last upper digestive tract screening-years (median and range) & $50(25-80)$ \\
Age at censory date (January 1 2009) $(N=27)$-years (median and range) & $52.0(33-81)$ \\
Positive family history $N(\%)$ & $24(75)$ \\
APC mutation known $N(\%)$ & $19(59.4)$ \\
First operation & \\
Subtotal colectomy and ileorectal anastomosis (IRA) $N(\%)$ & $20(62.5)$ \\
Proctocolectomy with ileal pouch anal anastomosis (IPAA) $N(\%)$ & $11(34.4)$ \\
Proctocolectomy with ileostoma $N(\%)$ & $1(3.1)$ \\
Operation status in 2009 $N(\%)$ & $11(34.4)$ \\
Subtotal colectomy and ileorectal anastomosis (IRA) $N(\%)$ & $13(40.6)$ \\
Proctocolectomy with ileal pouch anal anastomosis (IPAA) $N(\%)$ & $8(25.0)$ \\
Proctocolectomy with ileostoma $N(\%)$ & 210 \\
Total number of endoscopies $N$ & $6.5(2-17)$ \\
Number of endoscopies per patient (median and range) & $23(71.9)$ \\
Fundic glands present $N(\%)$ & $19.5(8-28)$ \\
Total follow-up in years (median and range) & $10(31.3)$ \\
Interrupted study due to endoscopic intervention $N(\%)$ & $5(15.6)$ \\
Interrupted study due to death $N(\%)$ & $8(25.0)$ \\
Participant of DAF study $N(\%)$ &
\end{tabular}

adenoma and three an endoscopic mucosal resection because of high grade dysplasia in a duodenal adenoma. These interventions were all performed in patients with Spigelman scores 10-12 and thus Spigelman stage IV in the period 2005-2009.

This cohort of 32 patients started their surveillance at a median age of 38 (13-65) years and at their first assessment most had Spigelman stage 0 or I $(65.6 \%)$, the remainder (approximately one-third) stage II, and none of the patients had stage III or stage IV (Table 3). The last endoscopy for this analysis was performed at a median age of 50 (25-80) years. At that time, 9 patients had Spigelman stage 0-II
(28.2\%), $28.1 \%$ stage III and $43.8 \%$ stage IV. In 2 patients the inclusion of the papilla resulted in a higher stage, progressing from stage II to IV.

The progression in duodenal adenomatosis within patients over time was studied as well. Two patients, 53 and 65 years old at their first screening endoscopy, had no duodenal polyps for 20 and 15 years, respectively. The first patient then progressed over 6 years to a stage IV polyposis at the age of 79, the other patient died from emphysema at the age of 80 years without polyps. Spigelman stages of 9 patients fluctuated between I and II (3 patients), II and III (4 patients) and III and IV (2 patients) over a median period 
Table 3 Comparison of Spigelman stages at first and last endoscopy

\begin{tabular}{lll}
\hline & $\begin{array}{l}\text { First endoscopy } \\
\text { at entry } N(\%)\end{array}$ & $\begin{array}{l}\text { Last endoscopy at the } \\
\text { completion of the study } \\
N(\%)\end{array}$ \\
\hline Stage 0 & $17(53.1)$ & $1(3.1)$ \\
Stage I & $4(12.5)$ & $2(6.3)$ \\
Stage II & $11(34.4)$ & $6(18.8)$ \\
Stage III & 0 & $9(28.1)$ \\
Stage IV & 0 & $14(43.8)$ \\
All & 32 & 32 \\
\hline & Median age (range) & Median age (range) \\
& at the first endoscopy & 80 \\
\hline Stage 0 & $38(13-65)$ & $59 ; 60$ \\
Stage I & $25.5(18-39)$ & $37.5(25-68)$ \\
Stage II & $43(25-51)$ & $40(29-66)$ \\
Stage III & - & $54.5(32-79)$ \\
Stage IV & - & $50(25-80)$ \\
All & $38(13-65)$ &
\end{tabular}

of 23 (range, 4-28) years with a median number of 8 endoscopies (range, 4-17). In 21 patients (66\%) a steady progression in stage was noticed. The time interval between two subsequent endoscopies when a change by one stage or by two stages was reported could be calculated for 49 episodes (Table 4). A median of 4 (range, 1-18) years elapsed in case of a one-stage change and a median of 7 (range, 1-28) years in case of a two-stage change.

Influence of time lapse on the course of the Spigelman score and stage

The number of years since the year of the start of the first screening endoscopy was a significant determining factor in the Spigelman score and stage over the years

Table 4 Duration of interval that elapses when the Spigelman staging system increases by one stage or by two stages

\begin{tabular}{lcc}
\hline & $\begin{array}{l}\text { Median } \\
\text { years }\end{array}$ & $\begin{array}{l}\text { Range } \\
\text { years }\end{array}$ \\
\hline Overall one stage higher (36 episodes) & 4 & $1-18$ \\
Change from stage 0 to I (6 episodes) & 3.5 & $3-18$ \\
Change from stage I to II (6 episodes) & 5 & $1-10$ \\
Change from stage II to III (15 episodes) & 4 & $1-15$ \\
Change from stage III to IV (9 episodes) & 4 & $1-8$ \\
Overall two stages higher (13 episodes) & 7 & $1-28$ \\
$\quad$ without intercurrent endoscopy & & \\
Change from 0 to II (8 episodes) & 6.5 & $1-28$ \\
Change from I to III (1 episode) & 11 & \\
Change from II to IV (4 episodes) & 4 & $1-13$ \\
\hline
\end{tabular}

1980-2009. Each year contributed 0.30 points to the Spigelman score and 0.12 to the stage (Table 5).

Influence of the endoscopic equipment on the course of the Spigelman score and stage

A significant effect of the change from fibre-endoscope to video-endoscope, from EVIS-100 to EVIS-130 and from Low to High Resolution equipment on the Spigelman score and stage was found. The older equipment resulted in a lower Spigelman score and stage (Table 5). For the fibreendoscope and for the lower resolution endoscope the estimate effects in lowering the Spigelman score and stage were greater than for the EVIS-100.

Influence of changed assessment of dysplasia on the course of the Spigelman score and stage

The change in the assessment of dysplasia according to the Vienna classification from 4 classes into 3 classes had a significant effect on the Spigelman score and Spigelman classification. The reporting of 4 classes of dysplasia resulted in a -3.37 points lower Spigelman score and a -1.47 lower Spigelman stage (Table 5).

Combined influences of time lapse, endoscopic equipment and changed assessment of dysplasia on Spigelman score and stage

When the effects of improved endoscopic equipment and changed dysplasia assessment were modulated by the time lapse, the time turned out to be dominant and significant in its effect on the Spigelman score and stage. Per year, the time lapse contributed between 0.24 and 0.36 points and between 0.09 and 0.15 stages (Table 5, Fig. 1). As to the endoscopic equipment a consistent and independent effect was seen with the EVIS processors and the Lower Resolution endoscopes. Also, the changed dysplasia rating influenced the Spigelman score and stage independently from the time lapse. Per year the time lapse contributed 0.27 points and 0.10 stages, whereas the old classification of dysplasia gave a lowering of the Spigelman score and stage by -1.33 points and -0.70 stages.

Combined influence of time lapse, endoscopic equipment and changed assessment of dysplasia on Spigelman score and stage with inclusion of the papilla

The inclusion of the papilla in the Spigelman score and classification resulted in a higher score and stage in 31 endoscopies. An influence of the endoscopic equipment independent from the time lapse was only present for the 
Table 5 Statistical analysis of the influence of time lapse, technical improvements and changes in pathology in the Spigelman score and stage

\begin{tabular}{|c|c|c|c|c|c|c|}
\hline $\begin{array}{l}\text { Dependent } \\
\text { factor }\end{array}$ & Fixed factor* & $\begin{array}{l}-2 \log \\
\text { likelihood }\end{array}$ & $\begin{array}{l}\text { Significance } \\
P \text { value } \\
\text { First factor }\end{array}$ & $\begin{array}{l}\text { Estimated effect }(95 \% \\
\mathrm{CI})^{* *} \\
\text { First factor }\end{array}$ & $\begin{array}{l}\text { Significance } \\
P \text { value } \\
\text { Second factor }\end{array}$ & $\begin{array}{l}\text { Estimated effect }(95 \% \\
\mathrm{CI})^{* *} \\
\text { Second factor }\end{array}$ \\
\hline \multirow{9}{*}{$\begin{array}{l}\text { Spigelman } \\
\text { score }\end{array}$} & Time lapse & 912.19 & $<0.001$ & $0.30(0.24 / 0.36) /$ year $)$ & & \\
\hline & Scope change 1 & $1,007.91$ & $<0.001$ & $-2.98(-4.04 /-1.91)$ & & \\
\hline & Scope change 2 & 995.44 & $<0.001$ & $-2.60(-3.35 /-1.84)$ & & \\
\hline & Scope change 3 & 957.54 & $<0.001$ & $-3.17(-3.80 /-2.54)$ & & \\
\hline & PA change & 994.19 & $<0.001$ & $-3.37(-4.32 /-2.41)$ & & \\
\hline & $\begin{array}{l}\text { Time lapse and scope } 1 \\
\text { change }\end{array}$ & 908.14 & $<0.001$ & $0.33(0.26 / 0.40) /$ year & 0.07 & $1.05(-0.09 / 2.19)$ \\
\hline & $\begin{array}{l}\text { Time lapse and scope } 2 \\
\text { change }\end{array}$ & 906.04 & $<0.001$ & $0.36(0.28 / 0.43) /$ year & 0.014 & $1.14(0.23 / 2.06)$ \\
\hline & $\begin{array}{l}\text { Time lapse and scope } 3 \\
\text { change }\end{array}$ & 906.47 & $<0.001$ & $0.24(0.17 / 0.31) /$ year & 0.018 & $-0.98(-1.79 /-0.17)$ \\
\hline & $\begin{array}{l}\text { Time lapse and PA } \\
\text { change }\end{array}$ & 903.29 & $<0.001$ & $0.27(0.20 / 0.33) /$ year & 0.003 & $-1.33(-2.20 /-0.46)$ \\
\hline \multirow{9}{*}{$\begin{array}{l}\text { Spigelman } \\
\text { stage }\end{array}$} & Time lapse & 562.55 & $<0.001$ & $0.12(0.09 / 0.14) /$ year & & \\
\hline & Scope change 1 & 648.02 & $<0.001$ & $-1.17(-1.62 /-0.72)$ & & \\
\hline & Scope change 2 & 638.99 & $<0.001$ & $-1.00(-1.32 /-0.68)$ & & \\
\hline & Scope change 3 & 597.67 & $<0.001$ & $-1.30(-1.57 /-1.04)$ & & \\
\hline & PA change & 627.07 & $<0.001$ & $-1.47(-1.87 /-1.07)$ & & \\
\hline & $\begin{array}{l}\text { Time lapse and scope } 1 \\
\text { change }\end{array}$ & 559.12 & $<0.001$ & $0.14(0.11 / 0.17) /$ year & 0.037 & $0.52(0.03 / 1.01)$ \\
\hline & $\begin{array}{l}\text { Time lapse and scope } 2 \\
\text { change }\end{array}$ & 554.80 & $<0.001$ & $0.15(0.12 / 0.18) /$ year & 0.002 & $0.62(0.23 / 1.02)$ \\
\hline & $\begin{array}{l}\text { Time lapse and scope } 3 \\
\text { change }\end{array}$ & 557.95 & $<0.001$ & $0.09(0.06 / 0.12) /$ year & 0.013 & $-0.44(-0.80 /-0.10)$ \\
\hline & $\begin{array}{l}\text { Time lapse and PA } \\
\text { change }\end{array}$ & 551.20 & $<0.001$ & $0.10(0.08 / 0.13) /$ year & $<0.001$ & $-0.70(-1.08 /-0.33)$ \\
\hline
\end{tabular}

* Scope 1 change: the replacement of fibre-endoscopes by video-endoscopes, scope 2 change: the change from EVIS-110 to EVIS-130-140 processors, scope 3 change: the replacement of Low Resolution by High Resolution endoscopes; PA change: replacement of the 4-grade dysplasia ranking by the 3 -grade ranking

** CI confidence interval, .../year increase of Spigelman in score or stage per year time lapse

Low and High Resolution endoscopes. Per year, the time lapse contributed 0.27 points and 0.11 stages to the Spigelman score and stage, respectively. The use of lower resolution endoscopes resulted in a lower Spigelman score $(-1.21$ points) and a lower stage ( -0.52 stages). Similarly, both the time lapse and the changes dysplasia assessment ranking had a significant impact. While the time lapse per year enhanced the Spigelman score with 0.30 points and the Spigelman stage with 0.12 stages, the old classification of dysplasia lowered the score and stage by -1.46 points and -0.78 stages, respectively.

\section{Discussion}

In this cohort of 32 patients, none presented with Spigelman stage III and IV disease at the start, whereas after a median of 19.5 years $72 \%$ of them have advanced duodenal polyposis stage III or IV. This is also reflected by the high number of patients $(31 \%)$ that underwent duodenal intervention and the one patient (3\%) who died from a periampullary cancer despite surveillance. This increase in duodenal polyposis over time has been confirmed by several others $[7,9,14,21]$. In previous studies, time since the diagnosis of FAP, age and the Spigelman stage at initial endoscopy were found to be determining factors for the severity of duodenal adenomatosis rather than gender or the site of the APC mutation [2, 7, 9, 22, 23].

In this study we demonstrated that improvements in endoscopic equipment over the years 1980-2009 have contributed to the Spigelman score and stage. For instance, whitish discoloured mucosa (harbouring adenomatous tissue) is increasingly more reported with the use of endoscopes with improved resolution, resulting in increased 
numbers of "polyps" for the Spigelman classification. Also the red discoloured central excavation in slightly raised, irregular shaped lesions at the apex of valvular folds are more readily appreciated with the newer endoscopes. If the time lapse since the first endoscopy, thus the ageing of the population, was also taken into consideration, only the High Resolution endoscopes showed an independent effect on the Spigelman score and stage. This effect was more impressive when the papilla was also included. Since we know that with older endoscopic equipments a normal appearing papilla showed adenomatous tissue in $50 \%$ of cases [18, 24, 25], this is probably due to the better visualization of the papilla resulting in better targeted sampling of an abnormal papilla. The change in the assessment of dysplasia had also an independent effect on the Spigelman score and stage.

In our cohort, the progression from one Spigelman stage to the next was slow with a median of 4 years, a finding generally confirmed by others. Heiskanen et al. [8] found a mean interval for the progression of stage 0 to stage I of 5.7 years, from I to II 4 years, from II to III 6 years and from III to IV 11 years (Table 6). Both Burke et al. [26] and Matsumoto et al. [27] also suggested that the worsening of duodenal polyposis with advancing age is a relatively slow process. Others report that duodenal adenomatosis is progressive in about $16-40 \%$ of cases or not at all [16, 25-31]. Alternatively, stable disease in $60 \%$ or even regression in $26 \%$ after an interval of 40 months has also been described [16, 26]. In our cohort two patients had no duodenal polyps for 15 and 20 years. Nine patients showed fluctuations of one stage over a median period of 23 years. Twenty-one patients $(66 \%)$ did progress over time with a median of 7 years before 2 higher stages were reached.

The percentage of patients with advanced disease may seem higher than reported in previous series. This seems to result from several methodological differences. Our follow-up was rather long with a median of 19.5 years, all endoscopies were performed at least with a forwardviewing (and since 1997 also sideward-viewing) endoscope, resulting in inspection of a larger area of the duodenum than in the original Spigelman publication [18]. Several investigators have shown the presence of adenomatous tissue in random biopsies [7, 18, 20, 24, 32]. Likewise, because we participated in the DAF study, we were used to take many biopsies and thus discovered

Table 6 Data on the distribution of Spigelman stage and changes therein in prospective studies [7-9, 14, 16, 18, 20, 21]

\begin{tabular}{|c|c|c|c|c|c|}
\hline & Stage $0(\%)$ & Stage I $(\%)$ & Stage II $(\%)$ & Stage III $(\%)$ & Stage IV $(\%)$ \\
\hline Spigelman $1989 n=102$ & 2 & 18.60 & 34.30 & 34.30 & 10.80 \\
\hline \multicolumn{6}{|l|}{ Mean age stage 0 -IV $33.5-51$ years } \\
\hline Nugent $1994 n=70$ & 4.30 & 17.10 & 25.70 & 38.60 & 14.30 \\
\hline \multicolumn{6}{|l|}{ Mean age stage $0-$ IV $40.7-50.4$ years } \\
\hline Bülow $1995 n=312$ & 30.10 & 17.30 & 26.60 & 16.70 & 9.30 \\
\hline \multicolumn{6}{|l|}{ Mean age stage $0-$ IV $37-40$ years } \\
\hline Bülow $2004 n=366$ & 33.60 & 15.00 & 26.50 & 17.40 & 7.40 \\
\hline \multicolumn{6}{|l|}{ Mean age 37 years, FU 7.6 years } \\
\hline Heiskanen $n=98$ & 45.90 & 34.70 & 14.30 & 3.10 & 2.00 \\
\hline Mean interval (years) between one stage change & 5.7 & 4 & 6 & 11 & \\
\hline Groves $2002 n=114$ & 2.60 & 13.2 & 38.60 & 36.00 & 9.60 \\
\hline \multicolumn{6}{|l|}{ Median age stage $0-$ IV $34-58$ years } \\
\hline Stage progression $N$ after 10 years of FU & 0 & 3 & 7 & 5 & 4 \\
\hline Saurin $2002 n=41$ & 0 & 12.20 & 17.10 & 34.10 & 36.60 \\
\hline Saurin $2004 n=35$ & 0 & 8.50 & 31.40 & 45.70 & 14.20 \\
\hline Mean age 37 years, FU 4 years & 0 & 8.50 & 17.10 & 31.40 & 42.80 \\
\hline Lepisto $2009 n=129$ & 30.20 & 36.40 & 19.40 & 12.40 & 1.60 \\
\hline \multicolumn{6}{|l|}{ Mean age 37 years } \\
\hline FU 8.5 years, $n=100$ & 8 & 17 & 41 & 18 & 16 \\
\hline \multicolumn{6}{|l|}{ Mean age 46 years } \\
\hline Current study Start $n=32$, mean age 36.8 years & 53.10 & 12.50 & 34.40 & 0 & 0 \\
\hline FU 18.4 years, $N=32$, mean age 50 years & 3.10 & 6.30 & 18.80 & 28.10 & 43.80 \\
\hline \multicolumn{6}{|l|}{ Mean interval (years) } \\
\hline -between one stage change & 6.7 & 5.2 & 5.1 & 4.3 & \\
\hline -between two stage change & 11 & 11 & 5.5 & & \\
\hline
\end{tabular}


adenomatous tissue in previously unsuspected areas. Finally, also the inspection of the papilla with targeted biopsies contributed to a higher Spigelman score, a finding confirmed by others [33].

As shown by our study as well as by others, the cumulative lifetime risk of developing duodenal adenomas is high, between 90 and $97 \%$ [2, 7, 8]. The cumulative risk of developing stage IV duodenal adenomatosis varies between 11 and 50\% [7-10, 14, 34]. Given that all FAP patients will develop duodenal adenomas which progress to stage IV in $30 \%$ of cases, the incidence of duodenal cancer, i.e. $3-5 \%$ in most studies, is surprisingly low [7-10].

Our findings of higher stages due to improved visibility and histology suggest that we might overestimate the clinical significance by using the Spigelman system. Therefore, we recently reviewed the data of our 160 FAP patients [35]. In 45 patients the classification was not yet known, mainly because of the young age of the subjects being children and grandchildren of our index cases. In the remaining 115 patients $67(58 \%)$ were classified as Spigelman III and IV and over one-third (26 patients) underwent endoscopic papillectomy, endoscopic mucosal resection and/or duodenectomy for severe duodenal polyposis. Although the Spigelman staging system has facilitated a better understanding of the natural history of duodenal polyposis, its use for risk-stratification has never been validated in a prospective study. In the light of the above findings, we believe that the Spigelman classification should be refined with a more balanced importance of polyp number, size and histology and including the papilla.

Open Access This article is distributed under the terms of the Creative Commons Attribution Noncommercial License which permits any noncommercial use, distribution, and reproduction in any medium, provided the original author(s) and source are credited.

\section{References}

1. Brosens LA, Keller JJ, Offerhaus GJ, Goggins M, Giardiello FM (2005) Prevention and management of duodenal polyps in familial adenomatous polyposis. Gut 54:1034-1043

2. Vasen HF, Moslein G, Alonso A et al (2008) Guidelines for the clinical management of familial adenomatous polyposis (FAP). Gut 57:704-713

3. Arvanitis ML, Jagelman DG, Fazio VW, Lavery IC, McGannon E (1990) Mortality in patients with familial adenomatous polyposis. Dis Colon Rectum 33:639-642

4. Gallagher MC, Phillips RK, Bulow S (2006) Surveillance and management of upper gastrointestinal disease in Familial Adenomatous Polyposis. Fam Cancer 5:263-273

5. Jagelman DG, DeCosse JJ, Bussey HJ (1988) Upper gastrointestinal cancer in familial adenomatous polyposis. Lancet $1: 1149-1151$

6. Offerhaus GJ, Giardiello FM, Krush AJ et al (1992) The risk of upper gastrointestinal cancer in familial adenomatous polyposis. Gastroenterology 102:1980-1982
7. Bulow S, Bjork J, Christensen IJ et al (2004) Duodenal adenomatosis in familial adenomatous polyposis. Gut 53:381-386

8. Heiskanen I, Kellokumpu I, Jarvinen H (1999) Management of duodenal adenomas in 98 patients with familial adenomatous polyposis. Endoscopy 31:412-416

9. Saurin JC, Gutknecht C, Napoleon B et al (2004) Surveillance of duodenal adenomas in familial adenomatous polyposis reveals high cumulative risk of advanced disease. J Clin Oncol 22:493-498

10. Vasen HF, Bulow S, Myrhoj T et al (1997) Decision analysis in the management of duodenal adenomatosis in familial adenomatous polyposis. Gut 40:716-719

11. Beckwith PS, van Heerden JA, Dozois RR (1991) Prognosis of symptomatic duodenal adenomas in familial adenomatous polyposis. Arch Surg 126:825-827

12. Debinski HS, Spigelman AD, Hatfield A, Williams CB, Phillips RK (1995) Upper intestinal surveillance in familial adenomatous polyposis. Eur J Cancer 31A:1149-1153

13. Griffioen G, Bus PJ, Vasen HF, Verspaget HW, Lamers CB (1998) Extracolonic manifestations of familial adenomatous polyposis: desmoid tumours, and upper gastrointestinal adenomas and carcinomas. Scand J Gastroenterol Suppl 225:85-91

14. Groves CJ, Saunders BP, Spigelman AD, Phillips RK (2002) Duodenal cancer in patients with familial adenomatous polyposis (FAP): results of a 10 year prospective study. Gut 50:636-641

15. Norfleet RG (1992) Screening for upper gastrointestinal neoplasms in patients with familial adenomatous polyposis and Gardner's syndrome. J Clin Gastroenterol 14:95-96

16. Nugent KP, Spigelman AD, Williams CB, Talbot IC, Phillips RK (1994) Surveillance of duodenal polyps in familial adenomatous polyposis: progress report. J R Soc Med 87:704-706

17. Kadmon M, Tandara A, Herfarth C (2001) Duodenal adenomatosis in familial adenomatous polyposis coli. A review of the literature and results from the Heidelberg Polyposis Register. Int J Colorectal Dis 16:63-75

18. Spigelman AD, Williams CB, Talbot IC, Domizio P, Phillips RK (1989) Upper gastrointestinal cancer in patients with familial adenomatous polyposis. Lancet 2:783-785

19. Schlemper RJ, Riddell RH, Kato Y et al (2000) The Vienna classification of gastrointestinal epithelial neoplasia. Gut 47: 251-255

20. Bulow S, Alm T, Fausa O, Hultcrantz R, Jarvinen H, Vasen $H$ (1995) Duodenal adenomatosis in familial adenomatous polyposis. DAF Project Group. Int J Colorectal Dis 10:43-46

21. Lepisto A, Kiviluoto T, Halttunen J, Jarvinen HJ (2009) Surveillance and treatment of duodenal adenomatosis in familial adenomatous polyposis. Endoscopy 41:504-509

22. Moozar KL, Madlensky L, Berk T, Gallinger S (2002) Slow progression of periampullary neoplasia in familial adenomatous polyposis. J Gastrointest Surg 6:831-837

23. Saurin JC, Ligneau B, Ponchon T et al (2002) The influence of mutation site and age on the severity of duodenal polyposis in patients with familial adenomatous polyposis. Gastrointest Endosc 55:342-347

24. Church JM, McGannon E, Hull-Boiner S et al (1992) Gastroduodenal polyps in patients with familial adenomatous polyposis. Dis Colon Rectum 35:1170-1173

25. Noda Y, Watanabe H, Iida M et al (1992) Histologic follow-up of ampullary adenomas in patients with familial adenomatosis coli. Cancer 70:1847-1856

26. Burke CA, Beck GJ, Church JM, van Stolk RU (1999) The natural history of untreated duodenal and ampullary adenomas in patients with familial adenomatous polyposis followed in an endoscopic surveillance program. Gastrointest Endosc 49:358-364

27. Matsumoto T (2000) Natural history of ampullary adenoma in familial adenomatous polyposis: reconfirmation of benign nature during extended surveillance. Am J Gastroenterol 95:1557-1562 
28. Alexander JR, Andrews JM, Buchi KN, Lee RG, Becker JM, Burt RW (1989) High prevalence of adenomatous polyps of the duodenal papilla in familial adenomatous polyposis. Dig Dis Sci 34:167-170

29. Bertoni G, Sassatelli R, Nigrisoli E et al (1996) High prevalence of adenomas and microadenomas of the duodenal papilla and periampullary region in patients with familial adenomatous polyposis. Eur J Gastroenterol Hepatol 8:1201-1206

30. Debinski HS, Trojan J, Nugent KP, Spigelman AD, Phillips RK (1995) Effect of sulindac on small polyps in familial adenomatous polyposis. Lancet 345:855-856

31. Iida M, Yao T, Itoh $\mathrm{H}$, Watanabe $\mathrm{H}$, Matsui $\mathrm{T}$, Iwashita A, Fujishima M (1989) Natural history of duodenal lesions in Japanese patients with familial adenomatosis coli (Gardner's syndrome). Gastroenterology 96:1301-1306
32. Domizio P, Talbot IC, Spigelman AD, Williams CB, Phillips RK (1990) Upper gastrointestinal pathology in familial adenomatous polyposis: results from a prospective study of 102 patients. J Clin Pathol 43:738-743

33. Latchford AR, Neale KF, Spigelman AD, Phillips RKS, Clark SK (2009) Features of duodenal cancer in patients with familial adenomatous polyposis. Clin Gastroenterol Hepatol 7:659-663

34. Bjork J, Akerbrant H, Iselius L et al (2001) Periampullary adenomas and adenocarcinomas in familial adenomatous polyposis: cumulative risks and APC gene mutations. Gastroenterology 121:1127-1135

35. Mathus-Vliegen EMH (2011) Reply. Jejunal cancer in patients with familial polyposis. Clin Gastroenterol Hepatol (in press) 